\title{
Parents' Perception and Parent-Adolescent Communication on Sexual Health in Southwest Nigeria
}

\author{
${ }^{1}$ Joyce Olufunke Ogunsanmi, ${ }^{2}$ Abiola Oyebimpe Olusanya, ${ }^{3}$ Oyewole Omoniyi Olusanya, \\ ${ }^{4}$ Ololade Omolayo Ogunsanmi \\ ${ }^{1}$ Ekiti State University, ${ }^{2}$ Federal University of Technology, ${ }^{2}$ Adekunle Ajasin Universisy, \\ ${ }^{3}$ Babcock University \\ ${ }^{1,2,3,4}$ Nigeria
}

\begin{abstract}
The issue of family intervention in adolescent's sexual health has become a global health concern because of increased sexual risk-taking behaviour among adolescents. A research question was raised to elicit information from respondents on parents' perception on communication on adolescents' sexual health. Also, one hypothesis was generated to examine the relationship between parents' perception and communication on adolescents' sexual health. The descriptive research of the survey type was adopted. Seven hundred and twenty-one (721) parents were purposively and proportionally selected using multi-stage random sampling techniques. A selfconstructed questionnaire was used. Data were analysed using descriptive and inferential analysis. The result shows that a majority of the respondents had proper perception on discussions on sexual health with adolescents. Also, parents' perception significantly influenced communication on adolescents' sexual health. The study recommends that parents and stakeholders should note the findings on the variables of interest and plan adequate counselling programmes.
\end{abstract}

\section{Introduction}

Adolescents' sexuality behaviour in Nigeria and sub-Saharan Africa appears to be undergoing great changes from what it used to be in the past. This could be attributed to the effect of westernization caused by industrialization, urbanization, education, exposure and enculturation through importation of various foreign cultures.

While parents never had to worry about the threats of social media in the past, it has become a matter of concern to them nowadays. Adolescents' rush into social media sites is a challenging subject to very many parents who have very little knowledge of social networking sites. There seems to be the need for parents to be more open with their adolescents because there are social and media pressures on adolescents to become sexually active [1]. Sexual risk taking behaviour places young people at an increased risk of infection with Human Immunodeficiency syndrome Virus (HIV) and other sexually transmitted infections (STIs) and unplanned pregnancy. Several indicators including family- based health education and wellbeing in communities make it imperative for the establishment of private counselling clinics where parents could be interacted with on issues on sexuality of adolescents [2].

It has been observed that school-based family life programmes are inadequate, except when parents are involved. Nonetheless, economic hardship and the need to survive under such hardship have hindered parental supervision and parent-adolescent intimacy that could enhance communication on adolescents' sexual health [3]. Although, it appears several factors influence adolescents' sexual health, parental factor seems the most important potential influence on adolescent's sexual behaviour because of the centrality of the family as a socialization agent. Parents are the first contact of a child. Therefore, parents serve as the first source of sex role. [4]. Hence, communication on adolescents' sexual health between parents or caregivers and offspring has been identified as a protective factor for a range of sexual behaviours. However, it appears not to be so in developing countries like Nigeria [5].

In spite of the overwhelming evidence of the need to involve parents in the comprehensive strategy for improving young people's health and development, there has been conflicting findings on whether parents in traditional African communities engage in sexualcommunication with their children. Many parents in Nigeria still confuse sexual health education with the act of encouraging children to sexual initiation. Hence parent-child discussion on sex-related matters often tailors to mere encouragement or admonition to their adolescents to avoid pre-marital sex [6]. A few of the parents provide detailed sexual health information to their children while many do not at all [7].

In view of the above outlined Sexual Health (SH) challenges and the needs of adolescents, it has been observed that improved parent-adolescent communication on sex-related matters could be enhanced with better parents' perception of adolescents' sexual health. Hence, this study examined parents' perception as a determinant of 
communication on adolescents' sexual health by parents in Southwest Nigeria.

The study raised the following research question: What is the extent of the perception of parents on adolescents' sexual health communication in Southwest Nigeria?

The following hypothesis was also formulated: Parents' perception will not significantly influence communication on adolescents' sexual health by parents in Southwest Nigeria.

\section{Methodology}

The descriptive research design of the survey type was adopted for the study. A total of 721 fathers and mothers in Southwest Nigeria, who had at least an adolescent child was used. The sample was selected through multi-stage sampling techniques. Data were collected using a self-developed questionnaire titled "Determinants of Parental Communication and Adolescents' Sexual Health (DPCASH). The selfconstructed instrument consisted of seven sections, AF. The instrument was validated using face, content and construct validity procedures. A construct validity coefficient of 0.75 was obtained. A reliability coefficient of 0.87 was obtained using test retest method of reliability. The instrument was selfadministered and retrieved from the respondents. Data were analysed using chi-square, frequency count and simple percentage.

\section{Results}

\subsection{Descriptive Analysis}

What is the extent of the perception of parents on adolescents' sexual health communication in Southwest Nigeria?

Table 1. Perception of Parents on Adolescents' Sexual Health Communication

\begin{tabular}{|c|c|c|}
\hline $\begin{array}{l}\text { P e r c e p t i o n o f } \\
\text { Parents on sexual health Communication }\end{array}$ & Frequency & Percentage\% \\
\hline Improper Perception & 157 & 21.8 \\
\hline Proper Perception & 562 & 78.2 \\
\hline $\mathrm{t}$ & 719 & 100 \\
\hline
\end{tabular}

The results on table 1 revealed that 562 (78.2\%) parents had proper perception of adolescents' sexual health discussion while 157 (21.8\%) had improper perception. It implies that a majority of the parents have proper perception of sexual health and sexuality of adolescents in Southwest Nigeria.

\subsection{Descriptive Analysis}

Hypothesis: Parents' Perception will not significantly influence communication on adolescents' sexual health by parents in Southwest Nigeria.

Table 2. Influence of Parents' Perception on Communication of Adolescents' Sexual Health.

\begin{tabular}{|c|c|c|c|c|c|c|}
\hline \multirow{2}{*}{$\begin{array}{l}\text { Parents' perception on } \\
\text { sexual health }\end{array}$} & \multicolumn{6}{|c|}{ Parental Communication on Sexual Health } \\
\hline & Poor & Good & Total & $\gamma^{2}$ & p-value & $\overline{\mathrm{Df}}$ \\
\hline Proper perception & $176(31.5)$ & $382(68.5)$ & 558 & inilo & 0.019 & 718 \\
\hline Improper perception & $69(43,0)$ & $92(57.0)$ & 161 & & & \\
\hline
\end{tabular}

Table 2 shows a significant result on perception of parents on communication on adolescents' sexual health $(\chi 2=5.372, p=0.019<0.05)$. The hypothesis was rejected. The magnitude of the influence was high and positive. This implies that perception of parents on adolescents' sexual health determined positive parental communication on adolescents' sexual health.

\section{Discussion}

The result revealed that a few parents in Southwest Nigeria have improper perception and a large number have proper perception of adolescents' sexual health discussion This result negates the finding of WHO (2011) which provided reasons why parent-child communication on sexual matters is difficult. It attributed the result to the belief of parents on sexual health information and that parents feel inadequately informed, embarrassed, and have difficulty finding a suitable time to talk with their children on matters relating to sexual health. Also, Obono [7] reported that in Nigeria, majority of parents believed that sexuality discussion with adolescents will result in promiscuity and their exposure to negative risky sexual behaviour. The possible reason for this result could be because nowadays, parents have been able to see the negative consequences of adolescents' risky sexual behaviour on their wellbeing in the society. Parents' perception significantly influenced communication on adolescents' sexual health. This is in agreement with Shams, Parhikar, S, Mousavizadeh, \& Majdpour, [8] and Mathew, Shugaba and Ogala [9] who revealed that parent-child communication on sexual matters was attributed to the perception of parents on sexual health. This finding indicates the relevance of the Theory of Planned Behaviour by Ajzen [10], which posited that belief plays a central role in human behaviour, especially those salient behavioural beliefs that are most readily accessible in 
memory. If parents' believe that discussions on sexual health information will lead to delayed sexual initiation or a prevention of risky sexual behaviour by their adolescents, they would have a positive attitude toward parent-adolescent communication on sexual matters.

\section{Conclusion}

It could be concluded that parents in Southwest Nigeria have relatively high and positive perception of communication on adolescents' sexual health. Also, parental communication on adolescents' sexual health by parents with their adolescent children is influenced by their perception on sexual health matters.

\section{Recommendations and Counselling Implications}

Wherever Times is specified, Times Roman or Times New Roman may be used. If neither is available on your word processor, please use the font closest in appearance to Times. Avoid using bitmapped fonts if possible. True-Type 1 fonts are preferred.

\section{References}

[1] Neil, C. \& Donald. (2015). Important life issues. European Scientific Journal, 11(20), 1857-7881.

[2] Ogunsanmi, J. O. (2007). Indicators for the need to establish private counselling clinics in Nigeria. Nigeria Journal of Counselling and Applied Psychology, 3 (1), 129 135

[3] Federal Ministry of Health. (2012). National strategic framework on the health and development of adolescents and Young people in Nigeria 2007 - 2011. Federal Ministry of Health, Abuja, Nigeria

[4] Henderson, V. (2006). The concept of nursing. Journal of Advanced Nursing, 53(1), 1365-2648.

[5] Graaf, H., Vanwesenbeek, I., Woertman, L., \& Meeus, W.H. (2010). Parenting and adolescents' sexual development in western societies.Journal of European Psychologist, 16(11), 21-31.

[6] World Health Organization. (2015). Brief sexuality related communication: Recommendations for a public health approach. Geneva: WHO.

[7] Obono, K. (2012). Patterns of mother-daughter communication for reproductive health knowledge transfer in Southern Nigeria. Global Media Journal- Canadian Edition, 5(1), 95-110.

[8] Shams, M., Parhikar, S., Mousavizadeh, A. \& Majdpour, M. (2017). Mothers view about sexual health education for their adolescents daughters: A qualitative study. Journal of Reproductive Health, 14(24), 1-7.

[9] Mathew, R.M., Shugaba, A.I., \& Ogala, W.N. (2006). Parents-adolescents communication and HIV/AIDS in Jos North Local Government Area, Plateau State, Nigeria. Journal of Medical Sciences, 6, 537-45.

[10] O Ajzen, I. (2002). Residual effects of past on later behaviour: Habituation and reasoned action perspectives. Personality and social psychology review, 6(2), 107-122. 